\title{
Perception of Female Doctors' Clinical Practice and Teaching in Anaesthesia and other Medical Specialties by Medical Students in Nigeria
}

\author{
Dr O.P. Adudu , Dr. O.G Adudub and Dr. E.E. Egibagibe
}

\begin{abstract}
More women are in medicine. The study aimed at examining medical students' perception of female doctors' clinical practice and teaching as it relates to their gender. The study's design was simple randomized using well-structured questionnaires. One hundred and sixtyone medical students with a mean age of $24.4 \pm 2$ years were involved in the study. Gender bias was shown generally by 68.9 of them with male doctors being favoured (42.9\%). Specialty preferences significantly favoured male surgeons (76 ie50.3\%) and female paediatricians (67 ie 44.9\%) ( $\mathrm{x}^{2}=10.78$ and 6.62 respectively, $\mathrm{p}<0.05$ for both). Preference for female anaesthetists (9.3\%) was better than has been reported (0.69\%). Majority of students (61.5\%) showed indifference to doctors gender as it relates to lecture delivery. The reasons adduced for these include socio-cultural misconceptions, gender concordance and sensitivity. We conclude that female doctors should improve their practice style and content and veer into male dominated specialties to clarify these misconceptions.
\end{abstract}

\section{INTRODUCTION}

There is a long history about females education in Nigeria. Culturally, apart from the traditional motherly role, females were equipped for

KEY WORDS: Doctors gender, clinical practice, teaching, medical students, perceptions.

asenior Lecturer/Consultant Anaesthesiologist, Department of Anaesthesiology, College of Medical Sciences, University of Benin, Benin City, Edo State, Nigeria. 'benior Consultant Surgeon / Zonal Medical Director, General Hospital, Ogwashi Uku, Delta State, Nigeria. 'Senior Lecturer/ Consultant Physician, Department of Medicine, University of Benin, Benin City, Nigeria.

Correspondence: Dr. O. P. Adudu, Department of Anaesthesia, College of Medical Sciences, University of Benin, Benin City, Edo State. Email: opadudu@yahoo.com.Tel: 08033313679

Presented as oral paper at international congress of Medical Women Intemational Association, Tokyo, Japan, July 2004. handcraft, weaving traditional clothes, pottery, trading including petty. This left occupations that need use of strength and risk taking to males, e.g. farming, hunting, building. Exceptions exist in certain parts where women farm (Delta region) and males do petty trading (Northern Nigeria) .

In the $20^{\text {th }}$ century, with the advent of western education female naturally veered into professions suited to their needs as regards time for child upbringing and household care, e.g. teaching, nursing and catering. At the beginning of the $21^{\text {st }}$ century, more females veered into male dominated professions, e.g. medicine, engineering, geology and architecture. Specifically for medicine, more female doctors are gradually incursing into general surgery anaesthesia

(c) CMS UNIBEN JMBR 2006; 5 (1): 7-12 
and obstetrics and gynaecology with less time suitability for household care. In the U.S.A., half the number of enrolled medical students are females ${ }^{1}$ and one in five of every physician was female by the year $2000^{2}$. In Nigeria, although there are no known figures, more females appear to be enrolling for medicine.

There are previous studies about patients and gender preferences for doctors both in the developed world $d^{3,4}$ and recently in Nigeria ${ }^{5}$. The former reviewed the difference in the practice style of male and female doctors. Interestingly, the latter revealed that male doctors were more favoured by gender biased patients. This aroused interest to study medical students' views about doctors' clinical practice and teaching as regards gender.

The aim of the study, therefore, is to examine medical students' perceptions of doctors' clinical practice and teaching in a tertiary institution in Nigeria, a developing country. The goal is to determine if there is gender bias as regards doctors' clinical practice and teaching and any influencing factors.

\section{METHODS}

The population sample of 350 was selected based on the 500 level medical students class rotating through Anaesthesiology department of the University of Benin for four months in 2004 . Seven clusters of 50 medical students was used for the study based on the small groups of 500 level medical students class (48 to 51 per group) that rotate through anaesthesiology for a two week period each to get good statistical representation. The simple random method was used to recruit 25 medical students from each cluster into the study. The total number of students in the study was 175. The sample instrument used were well-structured questionnaires containing closed and open ended questions as appropriate. They were distributed at the end of a well-attended lecture to each group. The closed questions included choice of gender for attending doctors' generally and in six medical specialties including anaesthesia, surgery, internal medicine, paediatrics, obstetrics and gynaecology and mental health. The choice of male or female doctors generally as regards teaching was also asked. Open ended questions for students demographic characteristics, reasons for relevant choices made including indifference and suggestions if any for improvement in their perceived notions were also sought.

Data entry and analysis was made using the statistical package for social sciences (SPSS) . Data is presented as frequency (\%) and / or mean with the following results including the umpaired t-test and standard deviation.

\section{RESULTS}

The total of one hundred and sixty-one 500 level medical students involved in the study included 79 males (49.1\%) and 82 females (50.9\%).This gave a response rate of $92 \%$ (175 questionnaires were sent out). The mean age of the medical students was $24.4 \pm 2$ years with a range of 21 to 31 years. All the students were single except one who was married $(0.6 \%)$.

One hundred and eleven medical students (68.9\%) showed gender bias for the attending doctor $-42.9 \%$ (69) in favour of male doctors and $26 \%$ (42) in favour of female doctors while 50 (31.1\%) were indifferent to the gender of the attending doctor. (Table 1) .

As regards medical students' preferences for doctors gender in specific medical specialties, they were basically indifferent in anaesthesia (92 ie 61.7\%), mental health (88 ie 59.1\%), internal medicine (80 ie 53.7\%) and obstetrics and gynecology (68 ie 45. 6\%). For surgery, male surgeons were most preferred (76 ie 50.3\%) and also female pediatricians ( 67 ie 45\%) (Table 2). Preference for female anaesthestists was by $9.3 \%$ (14) of students.

( C CMS UNIBEN JMBR 2006; 5 (1): 7-12 
Perception of Female Doctors' Clinical Practice and Teaching in Anaesthesia and other Medical Specialties. . . 9

Table 1: Preference for Gender of Attending Doctors by Medical Students

\begin{tabular}{|l|l|l|l|}
\hline \multirow{2}{*}{$\begin{array}{l}\text { Choice based on doctors } \\
\text { gender }\end{array}$} & \multicolumn{2}{|c|}{ Medical Students } & Total (\%) \\
\cline { 2 - 4 } & Male (\%) & Female (\%) & $69(100)$ \\
\hline Males & $35(50.7)$ & $34(49.3)$ & $42(100)$ \\
\hline Females & $20(47.6)$ & $22(52.4)$ & $50(100)$ \\
\hline Indifference & $24(48.0)$ & $26(52.0)$ & $161(100)$ \\
\hline TOTAL & $79(49.1)$ & $82(50.9)$ & \\
\hline
\end{tabular}

$X^{2}=0.29, p>0.05 . d f=2$

Table 2: Medical Students' Preference for Attending Doctors' Gender In Six Medical Specialties

\begin{tabular}{|c|c|c|c|c|c|c|c|}
\hline \multirow{2}{*}{\begin{tabular}{|l} 
Sex of \\
Medical \\
\end{tabular}} & \multicolumn{7}{|c|}{ Preference for doctors in 6 medical specialties } \\
\hline & Anaesthesia & Surgery & Int.Med & Paed. & $\mathrm{Ob} / \mathrm{Gyn}$ & Ment. health & Total [\%] \\
\hline Students & $\star_{\mathrm{M}} \mathrm{F} I$ & M F I & M F I & M F I & M F I & M F I & $437[48.8]$ \\
\hline MALES & 201439 & 45325 & 221438 & 123031 & 212329 & 24641 & $459[51.2]$ \\
\hline FEMALES & 91453 & 311631 & $15 \quad 18 \quad 42$ & 53734 & 122539 & 211047 & $896[100]$ \\
\hline TOTAL & $2928 \quad 92$ & $76 \quad 1956$ & 373280 & $1767 \quad 65$ & 334868 & 451688 & \\
\hline
\end{tabular}

Specialty specific calculated $x^{2}$ were all < expected $x^{2}=5.99$ at $d f=2$ except for surgery $x^{2}=10.78$ (expected 9.21) $p<0.01$, paediatrics $x^{2}=6.62$ (expected 5.99),$p<0.05$.

SPSS package was used for these associations which tested the level of significance of specialty preferences of medical students.

*M-male

F-female

Table 3: Medical Students' Preference for Doctors' Teaching Based on Gender

\begin{tabular}{|l|l|l|l|l|}
\hline \multirow{3}{*}{ Sex of students } & \multicolumn{3}{|c|}{ Preference for lecturers [\%] } \\
\cline { 2 - 5 } & $\begin{array}{l}\text { Male } \\
\text { Doctors }\end{array}$ & $\begin{array}{l}\text { Female } \\
\text { Doctors }\end{array}$ & Indifferent & Total \\
\hline Males & $26[32.9]$ & $7[8.9]$ & $46[58.2]$ & $79[100]$ \\
Females & $17[20.7]$ & $12[14.6]$ & $53[64.6]$ & $82[100]$ \\
\hline Total & $43[26.7]$ & $19[11.8]$ & $99[61.5]$ & $161[100]$ \\
\hline
\end{tabular}

$X^{2}=3.67, p>0.05, d f=2$

Table 2, I-indifference

Clinical teaching by male and female doctors was perceived indifferently with no gender bias by 99 (61.5\%) medical students. This was followed by preference for male doctors (43 ie $26.7 \%$ ) and female doctors (19 ie $11.8 \%$ ) clinical teaching Table 3.
The reasons adduced for indifference to the gender of the attending doctor generally was that both male and female doctors possessed the same knowledge and were equally competent and for gender biased medical students, reasons for preferences are as shown in Table 4. 
Table 4: Reasons Proferred for Choices Made by Gender Biased Medical Students (Contd)

\begin{tabular}{|c|c|c|}
\hline Aspect of study & $\begin{array}{l}\text { Male Doctor }[\%] \\
\mathrm{N}=69\end{array}$ & Female Doctors [\%] $\mathrm{n}=42$ \\
\hline $\begin{array}{l}\text { Clinical Practice } \\
\text { Clinical teaching }\end{array}$ & $\begin{array}{l}\text { - Better communication style } \\
\text { (more sympathetic, friendlier, } \\
\text { freer to talk to, exuding } \\
\text { confidence) - } 65 \text { ( } 94.2 \% \text { ) } \\
\text { - } \text { Better practice skills more } \\
\text { experienced, competent } \\
\text { (60 ie 87\%) dexterity; more } \\
\text { focused) } \\
\text { - Gender concordance } \\
\text { - Sociocultural factors (greater } \\
\text { strength suitability, less ruffled } \\
\text { by difficulties) (45 ie } 65.2 \% \text { ) } \\
\text { - Absence of female surgeons } \\
\text { (15 ie } 4.7 \% \text { ) } \\
\text { Good style of lecture delivery } \\
\text { (audible, livelier confident). } \\
30 \text { ( } 70 \% \text { ) } \\
\text { Good lecture content (detailed). } \\
26 \text { (60. } 5 \% \text { ) } \\
\text { Sympathetic to students on } \\
\text { difficulties encountered during } \\
\text { knowledge acquisition. } \\
18 \text { (41.9\%) }\end{array}$ & $\begin{array}{l}\text { - Gender sensitivity (motherly } \\
\text { spirit in paediatrics ) (40 ie 95.2\%) } \\
\text { - Gender specificity (ob/Gyn.) } \\
\text { (25 ie 59.5\%) sociocultural } \\
\text { factors (embarrassment by female } \\
\text { students body exposure during } \\
\text { clinical examination (38 ie 90.5\%), } \\
\text { arousal of erotic emotions in } \\
\text { male students by female doctors' } \\
\text { touch, (2 ie } 4.8 \% \text { ) avoidance of } \\
\text { possible sexual harassment of } \\
\text { females by male obs/Gyn. (3 ie } 7.1 \% \text { ) }\end{array}$ \\
\hline
\end{tabular}

The suggestions made by the medical students are as shown in Table 5.

Table 5. Suggestions made by Students

Basically on need for improvement in clinical practice and teaching by female doctors

- Encourage more female doctors into specialties dominated by males.

- Discourage interference of clinical work by household needs of female doctors. Restrict female doctors to specialties involving less stress, e.g. avoiding surgery, psychiatry, Ob/Gyn

- Need to talk more at public seminars to aid good lecture delivery and acquire confidence.

- Make lectures more audible (by use of public address systems) and livelier.
- Be more patient and tolerant, and enlighten the public about their capabilities.

- Better comportment and dressing, and need to pay less attention to students' dress - code, respect for elders, etc.

- Female doctors should be less strict and more approachable

- More participation of female doctors in administration is encouraged ( e.g Dean, M.D)

It was clear that all suggestions made including from those who were not gender biased (unexpected) tended towards the need for improvement in female doctors' style of practice / Clinical teaching.

\section{DISCUSSION}

It is interesting that medical students' perceptions of clinical skills and practice style of

(. CMS UNIBEN JMBR 2006; 5 (1): 7-12 
Perception of Female Doctors' Clinical Practice and Teaching in Anaesthesia and other Medical Specialties. . . 1 I

doctors including teaching favoured male doctors generally, as was found in a previous study in same locality using the patient ${ }^{5}$. They include male doctors having greater strength suitability for surgery and psychiatry than female doctors. Also, male doctors have better practice style including better communication and are more competent than their female colleagues. It was also illuminating that the reasons proferred for these were basically same as by the patients including practice style (communication). This suggests a definite need for Nigerian female doctors to improve on their practice style than the more subjective perceptions of their clinical skills and competence. It also contrasts with findings in the literature that women physicians communicate more effectively with patients. ${ }^{6,7}$ Reasons such as dexterity with the blade, greater strength to withstand stress and long hours of surgery and to stem psychiatric patients' violence better are not scientific and are based on socio-cultural background of medical students. It is worrisome that education did not deter these medical students from misconceptions to favour male doctors to the extent that some actually suggested that female doctors should specialise in less stressful specialties and not surgery, obstetrics and gynaecology and psychiatry.

Gender concordance and sensitivity played roles in reasons adduced for gender bias by male and female medical students. The male students definitely felt more comfortable with male doctors and perceived male doctors as more competent and confident relegating female doctors to a less competent group. In gender specific specialties of obstetrics and gynaecology and pediatrics, indifference and female doctors being marginally favoured to those showing indifference were choices made respectively. This is unlike reports in previous studies ${ }^{5}$ in Nigeria and the developed countries ${ }^{9}$ where female obstetricians ${ }^{9}$ and paediatricians ${ }^{5}$ were greatly favoured.
However, Howell et al ${ }^{10}$ found that a majority of their patients $(58 \%, n=39)$ were indifferent to the gender of their dostetricians with 34\% only preferring female obstetricians.

It is worrisome too that 500 level medical students were not aware of the job specifications of paramedical staff and that of the surgeons and psychiatrists. There are ward assistants to restrain violent psychiatric patients. Violence in these patients is also stemmed by prescription of the appropriate drugs by the doctor. The medical students may be unaware on the basis that their clinical posting in psychiatry is in the 600 level (final) year but not for surgery as they had previous primary posting (junior) at the 400 level year. The perception that female doctors were not competent as male surgeons is surprising since there were no female general surgeons in the study centre. Female resident doctors exist in otolaryngology and in ophthalmology where there are also female consultants. Evidence for this exist in the gender concordance seen among gender biased male students when they almost all preferred male surgeons.

The suggestions made by the medical students were mainly for improvement in style of practice and teaching skills of female doctors. This was not restricted to those who favoured male doctors but also those students who favoured female doctors and those who were indifferent. This suggests a definite need for female doctors to improve on their style of teaching and practice. It supports that gender concordance and sensitivity played roles among the female medical students who preferred female doctors. More medical students preferred female anaesthetists (15.2\%) than has been reported in the literature $(0.69 \%)^{11}$. This may be due to the introduction of bias by medical students who rotated through the department of anaesthesiology at the time of the study.

The greater number of female medical students involved in the study does not reflect the student population ratio but suggests that

( ) CMS UNIBEN JMBR 2006; 5(1) : 7-12 
more female students were regular at lectures. This did not however give bias to choices made as regards doctors' gender. This is further confirmed by the significant finding of preference for male surgeons and female pediatricians (Table 2) .

\section{CONCLUSION}

Nigerian medical students views about doctors clinical practice and teaching in a tertiary institution, clearly favoured male doctors with respect to communication style, practice style and content. Female doctors were found to be deficient in these areas. This is supported by suggestions proferred by the students (irrespective of gender bias or indifference) who wanted improvements in female doctors style of practice and communication including teaching. Nigerian female doctors in University of Benin specifically should strive to improve on their public relations, style of communication viz patient - doctor relationship and in clinical teaching. More females should also veer into male dominated specialties so as to clarify sociocultural misconceptions of greater strength suitability of the male doctor to surgery and psychiatry by the medical students.

\section{ACKNOWLEDGEMENTS}

I wish to thank the medical students who participated in the research. I also wish to thank the organizers of MWIA International Congress Tokyo, Japan, July 2004 for their contribution towards funding to make this paper presentation in Japan possible.

\section{References}

1 Association of American Medical Colleges Data Book: Statistical Information Related to Medical Schools and Teaching Hospitals.
Robinson L. ed Washington D.C American Association of Medical Colleges; 2000

2 Bowman M, Gross M.L Overview of research on women in medicine - issues for public policy makers. Public Health Rep 1986, 101, 5: 513:-521.

3. Arouni A.J., Rich E.C. Physician gender and patient care (Review) J GSM 2003, Vol. 6,1: $24-30$.

4. Schmittdiel J., Selby J.V., Grumbach K. , Quesenberry C.P.Jr. Choice of a personal Physician and patient satisfaction in a health maintenance organization. JAMA 1997; 278: 1596 - 1599.

5. Adudu O.P. Nigerian View of patient and gender issues in Medical specialties. Poster presentation World Congress of Anaesthesiologists, Paris April 2004 and published abstract on website of World Congress of Anaesthesiologists : www.wca2004.com

6. Bertakis K.D, Helms I.J, Callahan E.J. et al. The influence of gender on physician practice style. Med care 1995, 33: 407 - 416.

7. Roter D., Lipkin M.Jr., Korsgaard A. Sex differences in patients' and physicians communication during primary care medical visits. Med care 1991;29:1083 - 1093.

8. Chirman S.B. Preventive care for women: Does the sex of the physician matter? (letter) N Engl J Med 1994; 330: 215 discussion 216.

9. Adams K.E. Patient choice of provider gender. J. Am Med Womens' Assoc 2003, 58;2: $117-119$.

10. Howell E.A; Gaediner B; Concato J. Do women prefer female obstetricians? Obstet Gynecol 2002, 99;6: 1031 - 1035.

11. Zvara D. A., Nelson J. M., Broker R. F. et al Importance of postoperative visit: Do they improve patient or physician recognition? Anesth Analg 1996, 83; 4: 793 - 797. 